\title{
Research on the decision-making of return freight insurance considering consumer behavior under the omni-channel model
}

\author{
Xuebing Dong*1,a,Wenliang Bian ${ }^{2, \mathrm{~b}}$ \\ ${ }^{1}$ Beijing Jiaotong University, School of Economics and Management, Beijing, China \\ ${ }^{2}$ Beijing Jiaotong University, School of Economics and Management, Beijing, China
}

\begin{abstract}
This article considers that consumers choose offline returns under the omni-channel model to bring additional benefits to retailers, and studies the impact of different freight insurance delivery strategies on the pricing and consumer behavior of omni-channel retailers. Establish consumer utility function and corporate profit maximization model. Research has shown that consumers' satisfaction with the three ways that companies do not provide return freight insurance for consumers' online return, companies offer return freight insurance for consumers' online return, and companies do not provide return freight insurance for consumers' offline return when the price is high, free return shipping insurance can maximize the company's online benefits, while not providing return shipping insurance services can maximize the company's offline benefits, reducing commodity prices, and improving offline store service levels to further increase revenue; improve products Packaging quality to increase the net residual value of the product by ensuring the integrity of the product has a positive impact on increasing market share and corporate profits.
\end{abstract}

\section{Introduction}

The development trend of the omni-channel model is increasing. In 2020, Double Eleven has achieved the conversion of traffic-driven consumption by crossing multiple online platforms and channeling traffic, opening up channels to achieve interconnection. When consumers pick up goods offline, omni-channel retail stores will have the opportunity to obtain higher offline sales and more offline physical store traffic.

The large volume of online returns has stimulated conflicts between consumers and businesses. According to data released by the e-commerce newspaper, online consumption in the United States has hit a record high due to the epidemic, and the return rate of online consumption has reached $30 \%$. There are various return freight insurance delivery models. For merchants, there are no clear goals to choose a suitable return freight insurance delivery strategy to obtain more profits.

Relevant research on returns is mainly focused on online and offline channels. From the perspective of the supply chain, discussing pricing issues and return refund policies when considering returns. Liul considered the impact of three different return methods on the optimal pricing and profit of retailers in different channels, and proposed the return method for retailers. Javadi2 pointed out that using an indirect channel strategy for a full refund under the price incentive mechanism can maximize the profit of the supply chain while meeting government goals. Liu3explored the optimal pricing strategy of the dualchannel supply chain in consideration of retail services and consumer returns. Fan 4 studied the impact of the relationship between different channel combinations and channel return rates on commodity pricing and merchant profits. Nageswaran5 analyzed the impact of two return strategies, including full return and additional revenue, on retailer profits for both online and offline channels. Chen6analyzed the impact of consumer returns on different channel choices.

From the perspective of the business enterprise, it provides the strategy and management suggestions for the return freight insurance. Fan7considered the optimal delivery strategy of three different return freight insurances, compared three different return freight insurances. The introduction of insurance is not necessarily beneficial to businesses. Yang8found that sellers purchase freight insurance when the return rate is low, which is beneficial to improve the level of social welfare. Ying9 believe that merchants can increase the pre-sale price of goods after they provide return freight insurance. Lin 10 studied the optimal pricing and return strategy when retailers sell products to heterogeneous consumers with uncertain product values, as well as the value of freight insurance. Zheng11 believe that return freight insurance have a positive impact on consumers' purchase intentions. Ma12 believe that online sellers will eventually develop towards two strategies, neither buying freight insurance or buying freight insurance at all.

The innovation of this article, considering that consumers choose offline returns under the omni-channel model, may bring additional benefits to retailers, and study the impact of different freight insurance placement strategies on the pricing and consumer behavior of omni-

\footnotetext{
$\overline{a * d x b 1995 @ 163 . c o m}$

bwlbian@bjtu.edu.cn
} 
channel retailers, so as to provide retailers Provide better management suggestions. Studies have shown that when companies do not provide return freight insurance for consumers to return goods online, companies donate to provide return freight insurance for consumers to return goods online, and companies do not provide return freight insurance for consumers to return goods offline, when three business methods coexist, when consumers When you are satisfied with the product, if you want to get the maximum profit from the consumer's online return, you should give consumers free return shipping insurance. At this time, the price of the product can be appropriately increased; if you want to make more profits through offline returns, you should not Provide return freight insurance services, while reducing commodity prices, improving the service level of offline stores, and guiding consumers to bring additional benefits from offline secondary consumption; reducing logistics costs, improving product packaging quality to ensure product integrity, etc. The net residual value of commodities has a positive effect on increasing market share and corporate profits.

\section{Problem description and parameter assumptions}

This article considers a system composed of retailers and consumers in an omni-channel retail model, and conducts research on the delivery strategy of return freight insurance for the same product under different business models. Since the return freight insurance is provided by online sales, this article considers that when a product is sold to consumers online, companies can choose whether to give consumers return freight insurance. When consumers are not satisfied with the goods, they can use online channels or offline Channel returns. When a company presents consumers with return freight insurance, after the online return is successful, it is assumed that consumers only choose to return online because they can receive compensation from the insurance company. Based on the above assumptions, this article proposes the following three return freight insurance delivery models. The structure of omni-channel retail considering different return insurance delivery strategies is shown in Figure 1:

Model 1: Enterprises do not provide return freight insurance, consumers return online.

In this model, companies do not provide return freight insurance services. Consumers need to apply for return and sending online when returning goods, and consumers need to bear the freight when returning goods.

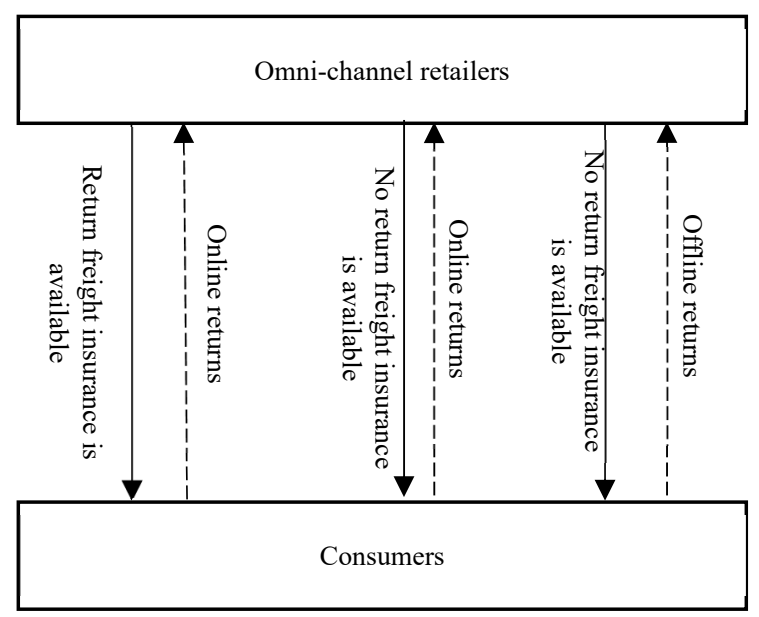

Figure 1 Return freight insurance strategy and return channel selection

Model 2: Enterprises offer return freight insurance, consumers return online.

In this model, the enterprise purchases return freight insurance for consumers, and an order is generated, the enterprise purchases a return freight insurance. When a consumer returns a product, the company receives and confirms the return before the consumer gets a claim from the insurance company.

Model 3: Enterprises do not offer return freight insurance, consumers return goods by offline.

Under this model, companies do not provide return shipping insurance. Consumers choose to return to offline stores when returning goods. It is assumed that when consumers return to offline physical stores, they will generate consumption and obtain additional utility, which will bring additional benefits to the enterprise.

Suppose the selling price of the product is $p$, the production and operating costs of the product are $c$, Consumers' perception of value obtained by purchasing products is $V$, in $[0,1]$ obey uniform distribution. Based on existing research, assuming that the consumer's perception of value after receiving the product is greater than the actual value of the product, it is regarded as the consumer's satisfaction with the product, assuming $\sigma$, $0 \leq \sigma \leq 1$, Consumers are dissatisfied with the product would return goods. Consumers returning goods online need to pay in advance the logistics cost $t$ of the mailed goods. When consumers return goods offline, the transportation expenses incurred to the physical store are $a$. The cost of the enterprise to purchase return freight insurance for consumers is set to $c_{1}$, and the return freight insurance is purchased when a consumer applies for an online return, he can receive the insurance company's shipping insurance claim fee as $b$. Assuming that the returned product's salvage value is $s$, the retailer will be brought to the retailer due to the consumer's secondary consumption when returning the product in an offline physical store. The income is $\omega$, and the consumer obtains the utility $u$ at this time. 


\section{Model building}

\subsection{No return freight insurance, return online}

When the company does not provide return freight insurance, the company allows the return but neither party purchases freight insurance. If the consumer is satisfied with the product, the utility obtained is $V-p$, if not satisfied, he needs to return the product online, and the consumer will follow the address provided by mailing to the company, while paying the logistics cost $t$, the utility obtained at this time is $0-t$. Under this strategy, the expected utility $U_{1}$ obtained by consumers is as follows:

$$
U_{1}=\sigma(V-p)-(1-\sigma) t
$$

When $U_{1} \geq 0$, that is, $V_{1} \geq(1-\sigma) t / \sigma+p$ consumers choose to buy goods. At this point, the retailer's market $D_{1}$ share is expressed as follows:

$$
D_{1}=1-\frac{(1-\sigma) t}{\sigma}-p
$$

The income obtained by the company after the product is sold is $\sigma p$, and the cost of the product is $c$. Assuming that the salvage value after the return of the product is $S$, the company's profit $\pi_{1}$ under this strategy is as follows:

$$
\pi_{1}=(\sigma p-c+s(1-\sigma))\left(1-\frac{(1-\sigma) t}{\sigma}-p\right)
$$

Proposition 1: In model 1, the retailer's optimal pricing $p_{1}^{*}$ is $((c+t(\sigma-1)+\sigma+s(\sigma-1))) / 2 \sigma$, and the maximum market share $D_{1}^{*}$ is $\Delta_{1} / 2 \sigma$, The retailer's maximum profit $\pi_{1}^{*}$ is $\Delta_{1}^{2} / 4 \sigma$. Among them, $\Delta_{1}=(\sigma-$ $c)+(1-\sigma) E_{1}, E_{1}=s-t$, the proof is omitted.

When market demand $D^{*}$ exists, it is necessary to ensure that $\Delta_{j} \geq 0$. For ease of analysis, similar to Ren13, let $E_{j}$ be the net residual value of the returned product, and set the net expected value as $\Delta_{j}=(\sigma-c)+(1-$ $\sigma) E_{j}, \sigma-c$ is the maximum net expectation value when the consumer is satisfied, $(1-\sigma) E_{j}$ is the net expectation value when the consumer is not satisfied.

Table 1 shows that without return freight insurance, the market share of the product and corporate profits will decrease, indicating that companies can reduce the cost of products to reduce sales. For returned products with large residual value, lower prices should be set, so that the sales of the products can be guaranteed, the loss rate is low, and the wear resistance can allow enterprises to recycle, reprocess or sell these products for a second time.

Under this model, the higher the logistics cost of returned goods, the more unfavorable the pricing and sales of goods. The net residual value and net expected value of the product increase, and the market share and profit of the company also increase, indicating that the company can increase its market share and corporate profit by reducing its logistics costs.

Table1. Relationships between online return parameters without return freight insurance service

\begin{tabular}{cccc}
\hline$M$ & $\frac{d p_{1}^{*}}{d M}$ & $\frac{d D_{1}^{*}}{d M}$ & $\frac{d \pi_{1}^{*}}{d M}$ \\
\hline$\sigma$ & $\downarrow$ & $\uparrow$ & $\uparrow$ \\
$c$ & $\uparrow$ & $\downarrow$ & $\downarrow$ \\
$s$ & $\downarrow$ & $\uparrow$ & $\uparrow$ \\
\hline
\end{tabular}

\begin{tabular}{cccc}
\hline$t$ & $\downarrow$ & $\downarrow$ & $\downarrow$ \\
$E_{1}$ & - & $\uparrow$ & $\uparrow$ \\
$\Delta_{1}$ & $\uparrow$ & $\uparrow$ & $\uparrow$ \\
\hline
\end{tabular}

\subsection{Offer return freight insurance, return online}

When the seller sends the return freight insurance, the utility obtained when the consumer is satisfied with the product is $V-p$, and the utility obtained when the product is not satisfied with the return is $b-t$, where $t$ is the logistics cost paid when the consumer chooses to return the goods online. In this mode, because the enterprise Free shipping insurance, so when consumers return the goods successfully, they can receive the insurance company's shipping insurance claims $b$. At this time, the expected utility for consumers is:

$$
U_{2}=\sigma(V-p)-(1-\sigma) t+(1-\sigma) b
$$

When $U_{2} \geq 0$, that is, $V_{2} \geq-((1-\sigma)(b-t)) / \sigma+$ $p$, the consumers choose to purchase the item. At this point, the retailer's market $D_{2}$ is expressed as:

$$
D_{2}=1+\frac{(1-\sigma)(b-t)}{\sigma}-p
$$

When a seller sends a return freight insurance, when an online consumer buys the enterprise's product, each order is generated, the enterprise automatically purchases a freight insurance for each order, assuming that the seller's cost for purchasing return freight insurance is $c_{1}$, the profit $\pi_{2}$ obtained by the enterprise under this strategy is as follows:

$$
\pi_{2}=\left(\sigma p-c-c_{1}+s(1-\sigma)\right)\left(1+\frac{(1-\sigma)(b-t)}{\sigma}-p\right)
$$

Proposition 2: In Model 2, the retailer's optimal pricing $p_{2}^{*}$ is $\left(\left(c+c_{1}+s(\sigma-1)-(b-t)(\sigma-1)+\right.\right.$ $\sigma)) / 2 \sigma$, and the maximum market share $D_{2}^{*}$ is $\left(\Delta_{1}+\right.$ $\left.(1-\sigma) b-c_{1}\right) / 2 \sigma$, the retailer's maximum profit $\pi_{2}^{*}$ is $\left(\Delta_{1}+(1-\sigma) b-c_{1}\right)^{2} / 4 \sigma$. Among them, $\Delta_{1}=(\sigma-$ $c)+(1-\sigma) E_{1}, E_{1}=s-t$, the proof is omitted.

Proposition 2 and Table 2 show that when a company purchases return freight insurance to provide consumers, the higher the price of the freight insurance purchased by the seller when the consumer returns the goods online, the higher the price of the product under the premise of ensuring profits. However, market demand for products and corporate profits will decrease. Therefore, companies can reduce the purchase of return freight insurance or reduce the return rate of online stores to achieve lower freight insurance prices by insurance companies.

After successfully receive the compensation for the logistics costs paid by the consumer $b$. The higher the compensation cost of the freight insurance, the greater the expected utility of the consumer's purchase of the goods. Therefore, the higher the insurance company's compensation for consumer freight insurance costs, it will not only improve consumer utility, but also conducive to product sales and corporate profitability.

Table2. Relationships between online return parameters when $\mathrm{D}$ provides return freight insurance

\begin{tabular}{cccc}
\hline$M$ & $\frac{d p_{2}^{*}}{d M}$ & $\frac{d D_{2}^{*}}{d M}$ & $\frac{d \pi_{2}^{*}}{d M}$ \\
\hline$\sigma$ & $\downarrow$ & $\uparrow$ & $\uparrow$ \\
\hline
\end{tabular}




\begin{tabular}{cccc}
\hline $\boldsymbol{c}$ & $\uparrow$ & $\downarrow$ & $\downarrow$ \\
$\boldsymbol{s}$ & $\downarrow$ & $\uparrow$ & $\uparrow$ \\
$\boldsymbol{t}$ & $\downarrow$ & $\downarrow$ & $\downarrow$ \\
$\boldsymbol{b}$ & $\uparrow$ & $\uparrow$ & $\uparrow$ \\
$\boldsymbol{c}_{1}$ & $\uparrow$ & $\downarrow$ & $\downarrow$ \\
$\boldsymbol{E}_{1}$ & - & $\uparrow$ & $\uparrow$ \\
$\Delta_{1}$ & $\uparrow$ & $\uparrow$ & $\uparrow$ \\
\hline
\end{tabular}

\subsection{No return freight insurance, return offline}

When the enterprise does not provide return freight insurance, the consumer does not have to pay the logistics cost of returning goods when returning goods offline, but the consumer returns offline may have transportation expenses $a$, The consumer needs to go to the physical store to return the goods offline. Assuming that when returning the goods in the physical store and the additional utility $u$ is obtained. The utility obtained by the consumer when returning the goods offline is $u-a$, and the consumer obtains The expected utility $U_{3}$ is as follows:

$$
U_{3}=\sigma(V-p)+(1-\sigma)(u-a)
$$

When $U_{3} \geq 0$, instantly $V_{3} \geq((1-\sigma)(a-u)) / \sigma+$ $p$, consumers will choose to buy goods. At this point, the retailer's market $D_{3}$ is expressed as:

$$
D_{3}=1-\frac{(1-\sigma)(a-u)}{\sigma}-p
$$

Assuming that the additional consumption $\omega$ when the consumer returns the return brings the benefits to the enterprise, at this time the enterprise profits under this strategy is as follows:

$$
\pi_{3}=(\sigma p-c+(s+\omega)(1-\sigma))\left(1-\frac{(1-\sigma)(a-u)}{\sigma}-p\right)
$$

Proposition 3: In model 3, the retailer's optimal pricing $p_{3}^{*}=(c+(s+\omega)(\sigma-1)+(a-u)(\sigma-1)+\sigma) / 2 \sigma$, maximum market share $D_{3}^{*}=\Delta_{2} / 2 \sigma$, and the retailer's maximum profit is $\pi_{3}^{*}=\Delta_{2}{ }^{2} / 4 \sigma . \Delta_{2}=(\sigma-c)+(1-$ $\sigma) E_{2}, E_{2}=s-a+u+\omega$.

Proposition 3 and Table 3 show that the more additional utility and consumption consumers can obtain in offline stores, the more beneficial the increase in corporate profits. At the same time, the greater the transportation cost, the more unfavorable the pricing of the goods and the profitability of the company. The cost of going to the store, and the higher the net residual value and expectations of the returned goods, the more profitable the company. Therefore, companies can give full play to the advantages of offline stores, improve consumer satisfaction, and guide consumers Secondary consumption increases corporate profits.

Table3. Relationships between offline return parameters without return freight insurance service

\begin{tabular}{cccc}
\hline $\boldsymbol{M}$ & $\frac{\boldsymbol{d} p_{2}^{*}}{\boldsymbol{d} \boldsymbol{M}}$ & $\frac{\boldsymbol{d} D_{2}^{*}}{\boldsymbol{d} \boldsymbol{M}}$ & $\frac{\boldsymbol{d} \boldsymbol{\pi}_{2}^{*}}{\boldsymbol{d} \boldsymbol{M}}$ \\
\hline $\boldsymbol{\sigma}$ & $\downarrow$ & $\uparrow$ & $\uparrow$ \\
$\boldsymbol{c}$ & $\uparrow$ & $\downarrow$ & $\downarrow$ \\
$\boldsymbol{s}$ & $\downarrow$ & $\uparrow$ & $\uparrow$ \\
$\boldsymbol{\omega}$ & $\downarrow$ & $\uparrow$ & $\uparrow$ \\
$\boldsymbol{a}$ & $\downarrow$ & $\downarrow$ & $\downarrow$ \\
$\boldsymbol{u}$ & $\uparrow$ & $\uparrow$ & $\uparrow$ \\
$\boldsymbol{E}_{2}$ & - & $\uparrow$ & $\uparrow$ \\
$\Delta_{2}$ & $\uparrow$ & $\uparrow$ & $\uparrow$ \\
\hline
\end{tabular}

\section{Analysis}

This section compares the changes in commodity prices, market shares and profits with satisfaction under the three freight insurance launch strategies, and obtains the following management enlightenment.

As shown in Figure 2 indicating that the company should consider the consumer's degree of satisfaction with the product when pricing the product. In addition, mode 2, that is, the enterprise provides consumers with free return freight insurance policy and guides consumers to return the goods online when the price of the goods is higher than the other two, because the company must consider the purchase of return freight insurance. Need to pay an extra fee when the time comes. Mode 3, that is, when the return freight insurance strategy is not provided to guide consumers to purchase offline, the goods under this strategy should be set at a lower price. In short, when guiding consumers to return goods offline, the price of goods should be lower than the price of goods returned online. When consumers return goods online, the price of goods when the company presents shipping insurance should be higher than the price of goods that do not provide return shipping insurance.

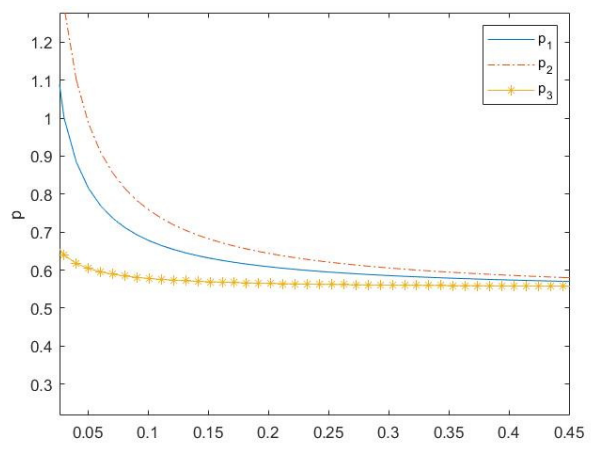

Figure 2 Between consumer satisfaction with the product and commodity prices

As shown in Figures 3 and 4, with the improvement of consumer satisfaction with products, market share and corporate profits are gradually increasing, indicating that companies should increase consumer satisfaction with products and thus increase the company's market. Share, increase profits. Mode 3, when consumers are more satisfied with the product, the market share and profits obtained by the company are the highest, followed by mode 2, when there is no return freight insurance service and consumers return goods online, the market share and corporate profits are the lowest. It shows that enterprises can guide consumers to return goods offline by not providing return freight insurance services, which can enable enterprises to obtain the largest market share and profits. If they want to obtain greater profits through consumer returns online, they should adopt mode 2 , which is to give consumers a gift Return freight insurance strategy. 


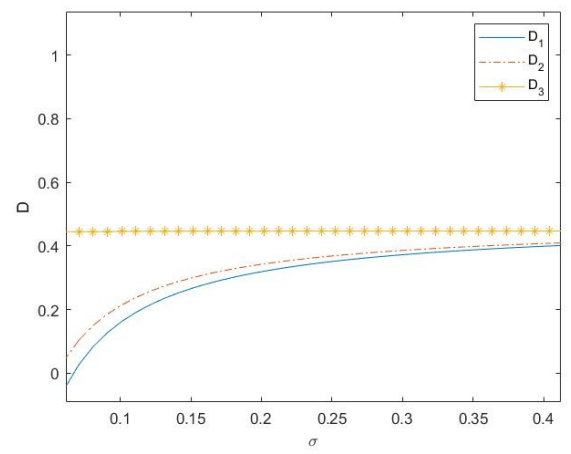

Figure 3 Between consumer satisfaction with the product and market share

As shown in Figure 5, the impact of consumer satisfaction and the residual value of returned goods on corporate profits under the three strategies. The greater the salvage value of the returned goods, the more conducive to corporate profitability. When the consumer's satisfaction with the product is constant, the greater the residual value of the returned product, the higher the corporate profit. Simple packaging is not conducive to the protection of the product, and the damage to the product by external damage indicates that the company should improve the quality of the packaging of the sold product, and then can ensure the second sale of the product by ensuring the integrity of the returned product.

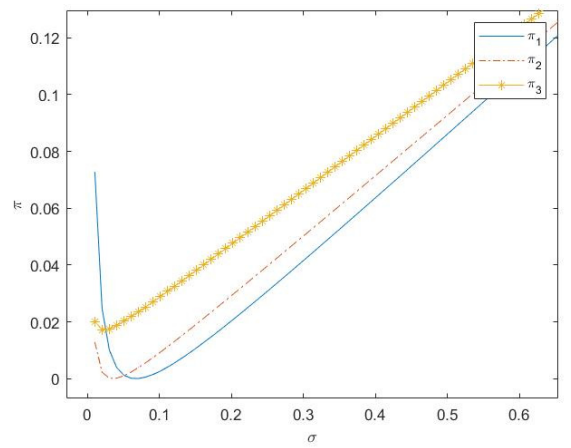

Figure 4 Between consumer satisfaction with the corporate profits

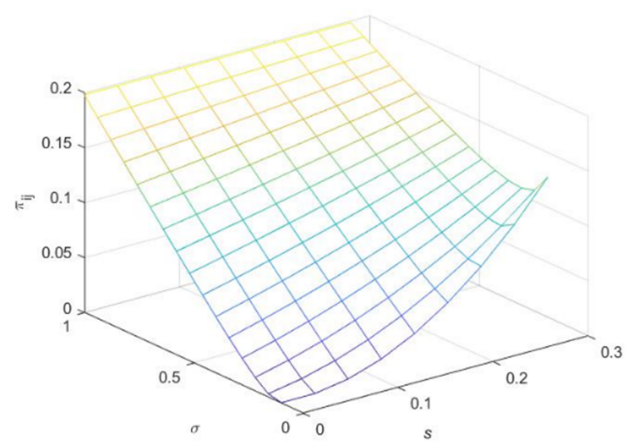

Figure 5 Consumer satisfaction with the product and the residual value of the returned item on the profits of the enterprise

\section{Conclusion}

This article takes into account the choice of consumer return channels under the omni-channel model, combined with the existing channel business model, and considers that under the omni-channel model, companies do not provide return freight insurance services, consumers online and offline returns and free consumer return freight insurance consumers. The impact of the three return and freight insurance delivery modes of online returns on the retailer's profit. Through the establishment of the retailer's profit function, the analysis of freight, return freight insurance price, additional income and consumer satisfaction with the product and other factors on the retailer's profit influences.

This study found that under the three modes, when consumers return goods online, the product price when the company does not provide return freight insurance service is lower than the price of the company sending consumers return freight insurance, although there will be additional costs when companies purchase return freight insurance. It is an expense, but it can increase market share and increase corporate profitability. Compared with online returns, products are priced at lower prices when returning goods offline, but this strategy has the highest market share and corporate profits. Since consumers return goods in physical stores when returning goods offline, it is conducive to secondary consumption and improve the company's profitability. Therefore, companies can not provide consumers with return freight insurance services, guide consumers to return goods offline, and at the same time improve offline service levels, increase additional revenue in the store, or give consumers free return freight insurance to guide consumers to return goods online, and at the same time increase the packaging quality of commodities reduces logistics costs and increases the net residual value of commodities.

There are also shortcomings in this article. The research process did not consider the loss caused by consumers when returning goods, and only considered the two strategies of shipping insurance delivery and return channel selection. In real life, the occurrence of returns is often accompanied by the depreciation of the goods, and there are still many business methods that need to be analyzed and compared.

\section{Acknowledgements}

Thanks for the opportunity provided by this meeting and the patient guidance of professor Bian for this article, the support of my parents, and the revision suggestions of reviewers.

\section{References}

1. Liu Jian, Zhang Yu, Chen Jie, et al. Research on return mode and pricing of Omni channel retailers [J]. Chinese Journal of Management Science, 2020, 1-12.

2. Javadi T, Alizadeh-Basban N, Asian S, et al. Pricing policies in a dual-channel supply chain considering flexible return and energy-saving regulations[J]. Computers \& Industrial Engineering, 2019, 135: 655674. 
3. Liu Yongmei, Zhou Di, Chen Xiaohong. BOPS channel integration considering service cost difference of offline retailers $[\mathrm{J}]$. Journal of systems engineering, 2018, 33 (01): 90-102.

4. Fandandan, xuqi, Cheng Fangzheng. O2o channel selection and decision optimization of brand makers considering the impact of return [J]. Chinese Journal of Management Science, 2019, 27 (11): 138-148.

5. Nageswaran L, Cho S, Scheller-Wolf A. Consumer Return Policies in Omnichannel Operations[J]. Management Science, 2020, 66(12).

6. Chen J, Bell P C. The impact of customer returns on supply chain decisions under various channel interactions[J]. ANNALS OF OPERATIONS RESEARCH, 2013, 206(1): 59-74.

7. Fan Z, Chen Z. When should the e-tailer offer complimentary return-freight insurance ? [J]. International Journal of Production Economics, 2020, 230: 107890.

8. Yang Lei, Chang Na. Decision making of supply chain operation considering return freight insurance [J]. Journal of systems engineering, 2018, 33 (01): 116-124.

9. He Yingying, Guo Chunxiang. Research on freight insurance decision-making based on strategic consumer return behavior under pre-sale mode $[\mathrm{J}]$. Chinese Journal of management, 2018, 15 (08): 12491255.

10. Lin J, Zhang J, Cheng T C E. Optimal pricing and return policy and the value of freight insurance for a retailer facing heterogeneous consumers with uncertain product values $[\mathrm{J}]$. International Journal of Production Economics, 2020, 229: 107767.

11. Zheng Chundong, Liu Yifan, Zou Meng. Influence of return freight insurance on online shopping consumers' purchase intention [J]. Journal of Shenyang University of Technology (SOCIAL SCIENCE EDITION), 2016, 9 (02): 150-156.

12. Ma Jianye, sun Jun. analysis of e-commerce sellers' freight insurance purchase strategy based on evolutionary game [J]. Journal of Beijing University of Chemical Technology (NATURAL SCIENCE EDITION), 2014, 41 (04): 117-120.

13. Ren M, Liu J, Feng S, et al. Pricing and return strategy of online retailers based on return insurance[J]. Journal of Retailing and Consumer Services, 2021, 59: 102350 . 